\title{
Desenvolvimento de um CNC para Confecção de Placa de Circuito e Antena de Microfita.
}

\section{Danielle Antunes Teixeira*, Guilherme Toledo Vieira da Silva*, Paulo José dos Santos*, Rodrigo Luiz Ximenes, Talía Simões dos Santos.}

\section{Resumo}

O projeto propõe a construção completa de uma máquina de CNC para confecção de placas de circuitos e antenas de microfita. Através da utilização de materiais de descarte e projeto de peças de acoplamento em impressora 3D, foi possível projetar o mecanismo mecânico e eletrônico que compõem os eixos $\mathrm{X}$, Y e Z. Para validação do equipamento, serão realizados testes com o software Eagle para circuitos e HFSS para antenas.

\section{Palavras-chave:}

Antena de Microfita, CNC, Microcontrolador.

\section{Introdução \\ Máquinas com Comandos Numéricos} Computadorizados (CNC) funcionam como robôs, que podem executar automaticamente suas funções sem a necessidade da constante atenção de um intermediário ${ }^{1}$. O processo de desenvolvimento de uma antena de microfita começa quando um software de desenho (como o Eagle ou o HFSS) manda informação para a placa microcontroladora (geralmente um arduino) que por sua vez envia os comandos para o $\mathrm{CNC}$ realizar.

As antenas de microfita são uma das maiores inovações no que diz respeito ao desenvolvimento de antenas nos últimos anos. Essas antenas possuem pequenas dimensões e são utilizadas em aplicações de altas freqüências ${ }^{2}$.

O projeto foi realizado com o objetivo de desenvolver uma máquina CNC para confecção de placas de circuitos e antenas de microfita. Sendo possível assim, introduzir os membros do projeto a área robótica, dando uma noção pratica dos processos envolvidos na produção de uma máquina computadorizada.

\section{Resultados e Discussão}

O trabalho iniciou-se de um plotter antigo de sucata. Foram removidos todos os itens mantendo apenas os eixos $X$ e $Y$, sem motores. Depois, foi realizada a construção dos suportes para adaptar 2 motores de passo modelo 17PM-J no eixo X e Y. Para o correto funcionamento foi embuchada, em ambos os motores, a engrenagem correspondente para uma relação de 1:10.

Para a fixação dos 2 motores necessitou-se de 3 peças de suporte desenhadas em AutoCAD e impressas em 3D utilizando filamento ABS. A Fig. 1a mostra o suporte do motor eixo $\mathrm{X}$ e a Fig. $1 \mathrm{~b}$ o suporte motor eixo $\mathrm{Y}$.

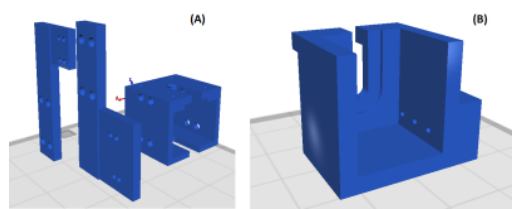

Figura 1. Suporte do motor. a. Do eixo X, b. do eixo $\mathrm{Y}$.

Em sequência foi necessário projetar os suportes da mesa para que ela ficasse plana.
Com os eixos $\mathrm{X}$ e $\mathrm{Y}$ prontos, foi projetado o carro da fresa, com um motor de passo, eixo roscável esférico, furadeira tipo Dremel, uma peça impressa em 3D, 2 guias lineares e 2 rodízios com esferas, vide Figura 2.

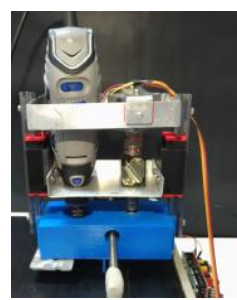

Figura 2. Conjunto desenvolvido.

A eletrônica foi feita usando o Arduino que recebe as coordenadas via USB e atua nos motores dos eixos através de uma Shield CNC. A alimentação total do sistema é realizada com uma fonte AT de computador com exceção da furadeira Dremel que é alimentada diretamente em $127 \mathrm{~V}$.

\section{Conclusões}

A máquina realiza com perfeição a fresa de placas de circuito e antenas. A resolução de movimentação foi o grande destaque do equipamento, pois permite construir placas de forma mais precisa $\mathrm{e}$ de tamanhos menores.

Evidencia-se a importância de reutilização de materiais que seriam descartados, pois com projeto e devidas alterações obteve-se um novo equipamento de trabalho na área de telecomunicações.

\section{Agradecimentos}

Agradecemos ao aluno de Engenharia de Telecomunicações André Henrique do Nascimento Cruz pelos auxílios no decorrer do projeto.

${ }^{1}$ INDUSTRIAL, Mecânica. Máquinas CNC. 2019. Disponível em: <https://www.mecanicaindustrial.com.br/maquinas-cnc-2/>. Acesso em: 22 jan. 2019

${ }^{2}$ SILVEIRA, R. V. L. Um Estudo Teórico sobre o uso das Antenas de Microfita. In: CONGRESSO NACIONAL DE EDUCAÇÃO, 3., 2016, Campina Grande - RN: Editora Realize, 2016. p. 1 - 6. Disponível em: <http://www.editorarealize.com.br/revistas/conedu/trabalhos/TRABALHO_ EV056_MD4_SA13_ID13630_19082016201940.pdf〉. Acesso em: 10 jan. 2019. 